\title{
Time Tested Practices for Mental Health Care During COVID-19 Epidemic and Beyond
}

\author{
Mauna Gauhar* \\ Mental health Professional, Director Growing Edge Consultants, F-10 Islamabad, Pakistan \\ *Corresponding author: Mauna Gauhar, Mental health Professional, Director Growing Edge Consultants, F-10 Islamabad, \\ Pakistan
}

\section{ARTICLE INFO}

Received: 慧 August 04, 2021

Published: 幽 August 13, 2021

Citation: Mauna Gauhar. Time Tested Practices for Mental Health Care During COVID-19 Epidemic and Beyond. Biomed J Sci \& Tech Res 38(1)-2021. BJSTR. MS.ID.006098.

\begin{abstract}
The pandemic of Coronavirus has caused great fear and loss to unprepared global population. The health ministry of Pakistan confirmed the outbreak in February 2020. Lockdowns, social distancing and quarantining were proposed by the government as protective measures to contain the virus which had mental health consequences. The drastic change in the daily routine and the closing down of the businesses and loss of life have disturbed huge segment of population. Pakistan being a low income country does not have sufficient mental health services available to deal with the Coronavirus situation. Hence some time tested Mental Health care practices such as relaxation therapy, mindfulness, breathing exercises, guided imagery, yoga and physical exercises are highlighted for the benefit of those who would like to manage these stress times and the experience of social distancing and quarantining productively.
\end{abstract}

Keywords: COVID 19; Psychoneuroimmunology Pakistan; Mental Health Care; Self-Help Techniques

\section{Introduction}

The pandemic of Corona- virus (COVIT 19) has not only shocked the world but also changed it. None of the hit countries were nearly prepared to deal with magnitude of the impact of this plague $[1,2]$. People responded to the contagion in different ways. Some experienced fear, anxiety and over reacted. Others maintained a total disregard for protective measures [3]. The first type of response caused dearth of commodities in the market through overbuying, stocking piling and hoarding of goods, food items, sanitizers, masks and medicines. The second response caused the epidemic to spread with rapid speed [4] resulting in hundreds and thousands of death across the globe. No one knows for sure how the world would look post COVID 19 [2]. However, what is known is that the world would be dealing with the consequences of high mortality, psychological distress and mental chaos brought on by the epidemic of Coronavirus [5]. The impact of COVID 19 on the global markets, professional work, economy, and health care systems has adversely impacted the mental health of people across the world [2]. The situation is further exacerbated by minimizing social interaction to curtail the spread of contagious disease through quarantining and social isolation [6]. A review of 24 studies revealed negative long lasting psychological consequences of quarantining including post trauma stress, anger and confusion [6]. Cases of domestic violence are reported to be on the rise and those vulnerable to it can't escape due to quarantine [7]. Quarantines and social distancing may be stressful but these can't be avoided in the times of epidemics as the spread of the contingent might be worst. Mental health practitioners predicted global increase in cases of anxiety and depression drug / alcohol use and abuse, sleep problems, self-harm and suicidal ideation $[8,9]$.

The outbreak of Coronavirus in Pakistan had been confirmed by the Health Ministry in February 2020 [10]. Since then, the Government of Pakistan advised partial Lock-downs, social distancing, quarantine and self-isolation to curtail the spread of epidemic. However, the situation is alarming as the cases of 
infection are on the rise. A segment of population is not adhering to the safety measures and recognized the seriousness of the situation [3]. Also the uncertainty about end of the endemic and loss of jobs has rendered many individuals susceptible to psychological crises which may negatively affect their immune system [11] and render them more vulnerable to fight Corona-virus in case of infection [12]. In almost every pandemic hit country, scientists and health professionals are endeavoring hard to find a cure to this highly contagious virus [2]. Till that happens no one knows for sure how many lives will fall victim to it. However, amidst this uncertainty, most health professionals agree that anyone with a strong immune system stands a better chance of fighting corona [12]. The science of psychoneuroimmunology that studies the interaction between neuroscience, psychological health and the immune processes is becoming popular among the researchers due to increased understanding of the part immune system play in health and disease [13]. Many studies conducted during 1990s and onwards explored the effects of psychological distress on immune system and found a strong link between nervous system and immune functioning [11]. American Psychological Association [14] found sufficient scientific evidence regarding adverse effect of stress and anxiety on the immune system.

To study the effects of life changing events including acute and persistent stressors on the immune system and if these changes in the immune system were moderated by the dispositional optimism, researchers found that in the face of persistent high level stress, the consequent immune decrement was higher for optimists than for the pessimists [15]. Another study reported human susceptibility to cold and flu as psychological stress exhausted immune protection against viral and bacterial infection in upper respiratory track [16]. Data also supported that the immune response of personalities described by negative affective disposition was low, which made them more at risk to infections and diseases than those described by positive affective disposition [17]. The mental health services utilization in Pakistan are low and the emergency guidelines for psychological crises interventions for public hit by corona are still awaited [18]. Although some comprehensive mental health protection/ support strategies and approaches for the policy makers had been highlighted by Mukhtar [18]; assuming responsibility for personal physical and mental health care would go a long way in stabilizing self and familial setup in these difficult times. The aim of this article is to propose research supported self-help interventions that people can easily adopt. These techniques could be useful in managing psychological distress during social distancing and selfisolation and would also help in stress management post COVID
19 endemic. Strong scientific evidence supports the effectiveness of these strategies in up-regulation of the immune functioning, remission of stress, anxiety, depression symptoms and improved physical and mental health. These self-care practices can also be used to avoid the negative experience of quarantine or make the experience as tolerable as possible [6].

\section{Relaxation Therapy}

Just as stress is the root cause of most physical and mental distress [19] relaxation trainings that induce relaxation response has huge physical and emotional implications. A number of studies reported that relaxation response interventions induce enhanced sleep [20] and increase health promoting behaviors. These interventions decrease anxiety, depression mental distress medical symptoms, headaches, medicinal intake, and stabilize bloodpressure [21]. Individuals who can't engage in physical workout can practice relaxation exercises to gain the benefits. There are many relaxation techniques such as progressive muscle relaxation, self-relaxation, and bio-feedback which can be adopted according to personal preferences. All of these have shown improvement in muscle tension, and increase ability to cope with stress [22]. Community and clinical population can equally benefit from relaxation training. For example, cancer patients who underwent mastectomy also showed significant improvement in their stress anxiety and depression levels after experiencing relaxation therapy [23].

\section{Mindfulness Meditation}

Non-judgmental attention to the sensations occurring in the moment is mindfulness. When the focus is on feelings sensations rather than content of the emotive thought, intense emotions can be managed [21]. Mindfulness relieves stress related negative symptoms, improves sense of well-being and induces positive mind-body states. A randomized control trial reported the results of mindfulness based stress reduction program on enhancing wellbeing. After eight weeks of training, subjects reported optimistic emotional states, such as a sense of ease, harmony, revitalization, vigor, positivity, cheerfulness, acceptance, and even experience of wholeness. There was a decrease in ruminative thought and results were maintained after one year follow-up period [24]. Another study that compared mindfulness meditation with somatic relaxation for stress reduction found both techniques equally effective in reducing stress however mindfulness meditation had showed a larger effect size for positive states of mind than just relaxation exercises [25]. 


\section{Breathing Exercises}

Breathing techniques are widely used for decreasing stress and anxiety. These improve the ability of respiratory system to produce energy from oxygen and remove waste [21]. Attentiveness to the way we breathe gives us the choice to modify shallow breathing to deep abdominal/ diaphragmatic breathing. Deep diaphragmatic breathing brings on relaxation and calms the aroused emotional states specific to anxiety and stress [26]. Studies have found that breathing exercise have positive effect on autonomous nervous system [27]. Slow breathing reduces stress by decreasing the hyper-arousal in the body (sympathetic activity) and increase the sense of calm (parasympathetic activity) [28]. It also has positive effects on cardiovascular [27] and respiratory functions [28]. Asthma patients can also benefits from it [29].

\section{Guided Imagery}

Guided imagery is used to replace negative thoughts with positive thoughts by means of imagination. Negative thoughts impact our emotional states, the way we conduct ourselves and worsen our physical symptoms. Refocusing mind on constructive healing images helps us to reduce the experience of stress and treat bodily symptoms [21]. The role of guided imagery in healing human mind and body has been the focus of research since decades. Guided imagery improves mood, decreases anxiety, depression, stress symptoms and up- regulates immune functions [30,31]. Patients suffering from multiple sclerosis, both relapsing and remitting, reported physical and mental wellbeing after experiencing it [32]. Guided imagery combined with progressive muscle relaxation had also been effectively used to manage cluster of symptoms in cancer patients receiving chemotherapy. They also reported improved quality of life. The researcher recommended its use to complement the existing treatment for cancer [33].

\section{Yoga}

Yoga is a discipline that combines physical stretches, breath trainings and concentration/meditation practices to create physical and psychological health and well-being [21]. Studies have shown that yoga practice elevates energy, creates bliss and contentment, improves social relationships, enhances sleep and overall health [34]. It has been successfully used with incarcerated women in correctional institution to improve their symptoms of anxiety, depression, and stress [35]. Yoga has scarcer contraindications and can be used as a complimentary treatment for psychiatric conditions [36]. According to Li, et al. [37] yoga is a promising option for mitigating stress and anxiety that underlie many chronic diseases and decreased quality of life. Research have investigated the effects of yoga on anxiety, depression, mood disturbance, performance anxiety, mental and physical stress, schizophrenia, addictive behavior, attention deficit disorder, autism, and obsessive compulsive disorder; and found it as an effective additional treatment for these conditions. It possibly treat symptoms that are left untreated by psychological and pharmacological interventions $[36,38-40]$.

\section{Exercise}

Sufficient amount of studies supports exercise as a protective factor for mental and physical wellbeing. Exercise activates immune system [41]. Physical workout has positive impact on anxiety, depression and on psychological, physiological and immunological functions. It also decreases inflammation in the body [42]. Hence aerobic exercises that increase the cardiac rate, [22] can easily be undertaken at home with the entire family (or alone). These could be static jogging, jumping, skipping or using television or YouTube to follow stronger workout programs such as cross-fit, aerobic workout, or palates etc. Physical workout releases mental and physical stress, elevate the symptoms of psychological suffering due to releasing endorphins and engage the family in meaningful and fun activity.

\section{Resilience}

The single most important factor that can help the nation to pass through the current testing time is resilience. Resilience helps people to thrive in hard times [43]. The above mentioned practices can be used in combination or as a single technique to calm down, stabilize, energize, emotionally regulate and build resilience against the challenges posed by COVID19 or any other stressful life event.

\section{Resource for Guided Practice}

Enough visual material exists in the form of pictures and videos on different websites including You-tube to guide the beginners. Most of these techniques are safe, and can be practiced at home through daily routine for someone with no health condition. The daily practice would go long way in building calm demeanor and prophylaxis.

\section{Recommendation}

The practices mentioned above are recommended for all who are experiencing adverse psychological symptoms due COVID19 or other stressful life events. This include health professional, caregivers and frontline workers, people working from home, essential staff, corona survivors, families and people from other walks of life. Those with serious medical or psychiatric/ psychological conditions should consult their doctors before undertaking these practices. The safest amongst the above mentioned techniques are the relaxation training, guided imagery and mindfulness meditation. Building good theoretical understanding of the techniques is always helpful for rewarding practice. 


\section{Conclusion}

The purpose of this article was to highlight some measures and practices which could help the nation in dealing with the stress caused by COVID 19. Each and every Pakistani is affected by the current existential crises. Hence the practices proposed are time tested and research supported techniques to calm the mind and body and bring relief from worry and concerns in the now and about the future. These practices are not substitutes for medication. Benefits can be observed immediately in some cases and in other cases regular practice needs to be maintained to experience optimum results.

The author is a clinical psychologist, clinical supervisor trauma therapist, trainer, yoga meditation instructor and Reiki master.

\section{References}

1. Ahmad T, Khan M, Khan FM, Hui J (2020) Are we ready for the new fatal Coronavirus: scenario of Pakistan? Human Vaccines \& Immunotherapeutics 16(3): 736-738.

2. Kumar A, Nayar KR ( 2020) COVID 19 and its mental health consequences. Journal of mental health 30(1): 1-2.

3. Shams S (2020) Coronavirus: Is Pakistan taking COVID-19 too lightly.

4. Khan S, Siddique R, Ali A, Xue M, Nabi G (2020) Novel coronavirus, poor quarantine, and the risk of pandemic. Journal of Hospital Infection 104(4): 449-450.

5. Xiao C (2020) A novel approach of consultation on 2019 novel coronavirus (COVID-19)-related psychological and mental problems: structured letter therapy. Psychiatry investigation 17(2): 175-176.

6. Brooks SK, Webster RK, Smith LE, Woodland L, Wessely S, et al. (2020) The psychological impact of quarantine and how to reduce it: rapid review of the evidence. The Lancet 395(10227): 912-920.

7. Graham Harrison E, Giuffrida A, Smith H, Ford L (2020) Lockdowns around the world bring rise in domestic violence. The Guardian, $28^{\text {th }}$ March.

8. Li W, Yang Y, Liu ZH, Zhao YJ, Zhang Q, et al. (2020) Progression of mental health services during the COVID-19 outbreak in China. International journal of biological sciences 16(10): 1732 .

9. Yao H, Chen JH, Xu YF (2020) Patients with mental health disorders in the COVID-19 epidemic. The Lancet Psychiatry 7(4): e21.

10. Saqlain M, Munir MM, Ahmed A, Tahir AH, Kamran S (2020) Is Pakistan prepared to tackle the coronavirus epidemic? Drugs \& Therapy Perspectives, p. 1-2.

11. Ziemssen T, Kern S (2007) Psychoneuroimmunology-cross-talk between the immune and nervous systems. Journal of neurology 254(2): 8-11.

12. Amene Saghazadeh, Nima Rezaei (2020) Immune-epidemiological parameters of the novel coronavirus - a perspective. Expert Review of Clinical Immunology 16(5): 465-470.

13. Pariante CM (2016) Neuroscience, mental health and the immune system: overcoming the brain-mind-body trichotomy. Epidemiology and psychiatric sciences 25(2): 101-105.

14. (2006) American Psychological Association. Stress weakens the immune system. American Psychological Association.

15. Cohen F, Kearney KA, Zegans LS, Kemeny ME, Neuhaus JM, Stites DP (1999) Differential immune system changes with acute and persistent stress for optimists vs pessimists. Brain, Behavior, and Immunity 13(2): 155-174.
16. Drummond PD, Hewson Bower B (1997) Increased psychosocial stress and decreased mucosal immunity in children with recurrent upper respiratory tract infections. Journal of psychosomatic research 43(3): 271-278.

17. Barak Y (2006) The immune system and happiness. Autoimmunity reviews 5(8): 523-527.

18. Mukhtar MS (2020) Mental Health and Psychosocial Aspects of Coronavirus Outbreak in Pakistan: Psychological Intervention for Public Mental Health Crisis. Asian Journal of Psychiatry 51: 102069.

19. Cohen S, Williamson GM (1991) Stress and infectious disease in humans. Psychological bulletin 109(1): 5-24.

20. Wang F, Lee OEK, Feng F, Vitiello MV, Wang W, et al. (2016) The effect of meditative movement on sleep quality: a systematic review. Sleep medicine reviews 30: 43-52.

21. Park ER, Traeger L, Vranceanu AM, Scult M, Lerner JA, et al. (2013) The development of a patient-centered program based on the relaxation response: the Relaxation Response Resiliency Program (3RP). Psychosomatics 54(2): 165-174.

22. Smith C, Hancock H, Blake Mortimer J, Eckert K (2007) A randomised comparative trial of yoga and relaxation to reduce stress and anxiety. Complementary therapies in medicine 15(2): 77-83.

23. Kashani F, Babaee S, Bahrami M, Valiani M (2012) The effects of relaxation on reducing depression, anxiety and stress in women who underwent mastectomy for breast cancer. Iranian journal of nursing and midwifery research 17(1): 30-33.

24. Amutio A, Martínezm Taboada C, Hermosilla D, Delgado LC (2015) Enhancing relaxation states and positive emotions in physicians through a mindfulness training program: A one-year study. Psychology health \& medicine 20(6): 720-731.

25. Jain S, Shapiro SL, Swanick S, Roesch SC, Mills PJ, et al. (2007) A randomized controlled trial of mindfulness meditation versus relaxation training: effects on distress, positive states of mind, rumination, and distraction. Annals of behavioral medicine 33(1): 11-21.

26. Hazlett Stevens H, Craske MG (2009) 14 Breathing Retraining and Diaphragmatic Breathing. General principles and empirically supported techniques of cognitive behavior therapy.

27. Mourya M, Mahajan AS, Singh NP, Jain AK (2009) Effect of slow-and fastbreathing exercises on autonomic functions in patients with essential hypertension. The journal of alternative and complementary medicine 15(7): 711-717.

28. Pal GK, Velkumary S (2004) Effect of short-term practice of breathing exercises on autonomic functions in normal human volunteers. Indian Journal of Medical Research 120(2): 115-121.

29. Thomas M, McKinley RK, Mellor S, Watkin G, Holloway E, et al. (2009) Breathing exercises for asthma: a randomised controlled trial. Thorax 64(1): 55-61.

30. Gruzelier JH (2002) A review of the impact of hypnosis, relaxation, guided imagery and individual differences on aspects of immunity and health. Stress 5(2): 147-163.

31. Trakhtenberg EC (2008) The effects of guided imagery on the immune system: A critical review. International Journal of Neuroscience 118(6): 839-855.

32. Case LK, Jackson P, Kinkel R, Mills PJ (2018) Guided Imagery Improves Mood, Fatigue, and Quality of Life in Individuals with Multiple Sclerosis: An Exploratory Efficacy Trial of Healing Light Guided Imagery. Journal of evidence-based integrative medicine 23: 2515690X17748744.

33. Charalambous A, Giannakopoulou M, Bozas E, Marcou Y, Kitsios P, et al. (2016) Guided imagery and progressive muscle relaxation as a cluster of symptoms management intervention in patients receiving chemotherapy: a randomized control trial. PLoS One 11(6): e0156911. 
34. Ross A, Friedmann E, Bevans M, Thomas S (2013) National survey of yoga practitioners: mental and physical health benefits. Complementary therapies in medicine 21(4): 313-323.

35. Harner H, Hanlon AL, Garfinkel M (2010) Effect of Iyengar yoga on mental health of incarcerated women: A feasibility study. Nursing research 59(6): 389-399.

36. Cabral P, Meyer HB, Ames D (2011) Effectiveness of yoga therapy as a complementary treatment for major psychiatric disorders: a metaanalysis. The primary care companion to CNS disorders 13(4): 1068.

37. Li AW, Goldsmith CAW (2012) The effects of yoga on anxiety and stress. Alternative Medicine Review 17(1): 21-35.

38. Khalsa SS (2013) Yoga for Psychiatry and Mental Health: An Ancient Practice with Modern Relevance. Indian J Psychiatry 55(7): 334-336.

ISSN: 2574-1241

DOI: 10.26717/BJSTR.2021.38.006098

Mauna Gauhar. Biomed J Sci \& Tech Res

CC This work is licensed under Creative BY Commons Attribution 4.0 License

Submission Link: https://biomedres.us/submit-manuscript.php
39. Khalsa SBS, Shorter SM, Cope S, Wyshak G, Sklar E (2009) Yoga ameliorates performance anxiety and mood disturbance in young professional musicians. Applied Psychophysiology and Biofeedback 34(4): 279-289.

40. Telles S, Singh N, Balkrishna A (2012) Managing mental health disorders resulting from trauma through yoga: a review. Depression research and treatment.

41. Timmons BW (2005) Paediatric exercise immunology: health and clinical applications. Exerc Immunol Rev 11: 108-144.

42. Mikkelsen K, Stojanovska L, Polenakovic M, Bosevski M, Apostolopoulos V (2017) Exercise and mental health. Maturitas 106: 48-56.

43. Davydov DM, Stewart R, Ritchie K, Chaudieu I (2010) Resilience and mental health. Clinical psychology review 30(5): 479-495.

$\begin{array}{ll}\text { BIOMEDICAL } & \text { Assets of Publishing with us } \\ \text { RESEARCHES } & \text { - Global archiving of articles } \\ \text { - Immediate, unrestricted online access }\end{array}$

